\title{
ESTUDOS ECOTOXICOLÓGICOS DE LIXIVIADO DE ATERRO SANITÁRIO ANTES E APÓS VÁRIAS ETAPAS DO TRATAMENTO
}

\author{
Laís Yuko Suzuki \\ Aline Domingues Batista \\ Emília Kiyomi Kuroda
}

RESUMO: A decomposição física, química e biológica de resíduos sólidos domiciliares em aterros sanitários resulta na produção de um líquido de coloração escura, chamado de lixiviado. Este lixiviado apresenta uma grande heterogeneidade na sua composição e pode ter como características elevadas concentrações de nitrogênio amoniacal, matéria orgânica, compostos de difícil degradação e eventualmente metais. Devido as suas características, este requer um tratamento adequado para que os valores de seus parâmetros físicos, químicos e biológicos atendam aos limites estabelecidos pela legislação vigente e que não cause impactos ao meio ambiente. Assim, é de fundamental importância que as pesquisas relacionadas ao meio ambiente sejam desenvolvidas associando-se as análises físico-químicas e os ensaios ecotoxicológicos. Dessa forma, o objetivo deste trabalho foi realizar ensaios de ecotoxicidade com os organismos-teste: Pseudokirchneriella subcapitata, Ceriodaphnia dubia, Daphnia magna e Artemia salina em lixiviado estabilizado de aterro sanitário e após tratamento biológico e físico-químico composto por coagulação química-floculação-sedimentação. Os resultados dos ensaios de ecotoxicidade mostraram que após o tratamento biológico, o lixiviado apresentou menor toxicidade frente aos organismos-teste. Já para o lixiviado pós-tratado por coagulação-floculação-sedimentação, apesar da remoção significativa de compostos recalcitrantes, houve aumento de toxicidade para $P$ subcapitata, $C$. dubia e $D$. magna.

Palavras-chave: Ecotoxicidade. Lixiviado. Organismo-teste 


\section{INTRODUÇÃO}

A decomposição física, química e biológica de resíduos sólidos domiciliares em aterros sanitários resulta na produção de um líquido de coloração escura, chamado de lixiviado, percolado ou chorume. Este efluente tem como característica altas concentrações de nitrogênio amoniacal, matéria inorgânica e compostos orgânicos de difícil degradação, como as substâncias húmicas, além de compostos tóxicos ao meio ambiente. Além disso, o lixiviado gerado nos aterros sanitários apresenta grande variabilidade na sua composição química, que, por sua vez, depende de vários fatores como a idade do aterro, as condições geológicas, locais e eventos climáticos diversos.

Vale ressaltar que mesmo quando os resíduos sólidos são depositados no solo adequadamente e o aterro encerra suas atividades, a geração do chorume não se "extingue" e, em geral, quanto mais velho $\mathrm{o}$ aterro, menos biodegradável ou mais estabilizado é esse efluente, necessitando de processos de tratamento adicionais e muitas vezes mais complexos. Em função dessas características, o tratamento por processos biológicos é dificultado e requer o emprego de processos físicos e químicos complementares a exemplo dos que compõem a técnica de ciclo completo (coagulação floculação - sedimentação).

Por outro lado, sabe-se que as análises físicas e químicas não são capazes de distinguir entre as substâncias que afetam os sistemas biológicos e as que são inertes ao meio ambiente. Desta forma, há necessidade de se controlar a qualidade do efluente, de forma que este não cause efeitos tóxicos de natureza aguda ou crônica à biota aquática. Assim, é de fundamental importância que as pesquisas relacionadas ao meio ambiente sejam desenvolvidas associando-se as análises físico-químicas e ensaios ecotoxicológicos.

Segundo Magalhães e Ferrão Filho (2008), os ensaios ecotoxicológicos permitem avaliar a contaminação ambiental por diversas fontes de poluição e tem como vantagem, abranger uma grande variedade de substâncias biologicamente disponíveis em uma amostra ambiental através de um único ensaio. Detectam a capacidade inerente de um 
agente tóxico ou uma mistura, em produzir efeitos deletérios nos organismos vivos, permitindo avaliar em que medida essas substâncias são nocivas.

Os ensaios de ecotoxicidade foram incorporados na Resolução 357/2005 do Conselho Nacional do Meio Ambiente - CONAMA. No Capítulo IV desta resolução, no que diz respeito às condições e padrões de lançamento de efluentes, é estabelecido nos $\S 1$ e 2 do Artigo 34, que o efluente não deverá causar ou possuir potencial para causar efeitos tóxicos aos organismos aquáticos no corpo receptor, e que os critérios de toxicidade devem se basear em resultados de ensaios ecotoxicológicos padronizados, utilizando organismos aquáticos.

Nesse contexto, os ensaios de ecotoxicidade tem sido incluídos nas recentes atualizações das legislações brasileiras (CONAMA 357/2005; CONAMA 430/2011; CEMA №. 0070/2009; CEMA №. 081/2010), sendo assim, de fundamental importância a consideração da toxicidade, além dos parâmetros físicos e químicos na avaliação de desempenho dos sistemas de tratamento de lixiviados, visando a preservação do meio ambiente aquático.

O objetivo geral deste trabalho foi realizar ensaios de ecotoxicidade com os organismos-teste: Pseudokirchneriella subcapitata, Ceriodaphnia dubia, Daphnia magna e Artemia salina em lixiviado estabilizado de aterro sanitário e após tratamento biológico e físico-químico composto por coagulação química-floculação-sedimentação.

\section{MATERIAIS E MÉTODOS}

\subsection{Lixiviado de estudo}

O lixiviado bruto foi coletado no aterro controlado de resíduos sólidos domiciliares da cidade de Londrina - PR, com características de lixiviado estabilizado. Este foi submetido aos seguintes tratamentos:

- Tratamento preliminar por stripping de amônia seguido de tratamento biológico;

- Pós-tratamento por coagulação-floculação-sedimentação;

As amostras foram codificadas conforme a Tabela 1. 
Tabela 1 - Códigos das amostras utilizadas nos ensaios de ecotoxicidade

\begin{tabular}{c|c}
\hline Nome da amostra & Código \\
\hline Lixiviado Bruto & LIX \\
\hline Lixiviado pré-tratado por stripping de amônia seguido de tratamento biológico & BIO \\
\hline Lixiviado pós-tratado por coagulação-floculação-sedimentação & CFS \\
\hline
\end{tabular}

A caracterização física e química do lixiviado bruto e do lixiviado tratado biologicamente foi realizada segundo parâmetros e métodos analíticos, descritos em APHA, AWWA, WEF (2005), conforme a Tabela 2. Já após o pós-tratamento por coagulação-floculação-sedimentação foram avaliados os parâmetros pH, cor aparente, cor verdadeira, DQO, COT e cloreto.

Tabela 2 - Parâmetros físico-químicos e métodos utilizados

\begin{tabular}{|c|c|c|c|}
\hline PARÂMETRO & $\begin{array}{l}\text { Ref. APHA, AWWA, } \\
\text { WEF (2005) }\end{array}$ & MÉTODO & $\begin{array}{l}\text { EQUIPAMENTO } \\
\text { (MODELO/MARCA) }\end{array}$ \\
\hline $\mathrm{pH}$ & $\begin{array}{l}\text { Potenciométrico } \\
4500\end{array}$ & Método potenciométrico & $\begin{array}{l}\text { pHmetro: Digimed DM-2P } \\
\text { Agitador: FISATOM } 761\end{array}$ \\
\hline Temperatura (oC) & - & Termômetro de Hg & - \\
\hline $\begin{array}{l}\text { Alcalinidade } \\
\text { (mg CaCO3 L-1) }\end{array}$ & $2320 \mathrm{~B}$ & Método titulométrico & $\begin{array}{l}\text { pHmetro: Digimed DM-2P } \\
\text { Agitador: FISATOM } 761 \\
\text { Titulador: METROHM } 20 \mathrm{~mL}\end{array}$ \\
\hline Cor aparente (uH) & $2120 \mathrm{C}$ & Método espectrofotométrico & Espectrofotômetro BEL 1105 \\
\hline Cor verdadeira $(\mathrm{uH})$ & $2120 \mathrm{C}$ & $\begin{array}{c}\text { Método espectrofotompetrico } \\
\text { - filtrado em membrana } 0,45 \\
\mu \mathrm{m}\end{array}$ & Espectrofotômetro BEL 1105 \\
\hline $\begin{array}{l}\text { Série de sólidos } \\
\left(\mathrm{mg} \mathrm{L}^{-1}\right)\end{array}$ & $2540 \mathrm{~B}, \mathrm{C}, \mathrm{D} \mathrm{E}$ & $\begin{array}{c}\text { Sólidos totais secos a 103- } \\
105 \circ \mathrm{C} \\
\text { Sólidos totais dissolvidos } \\
\text { secos a } 180^{\circ} \mathrm{C} \\
\text { Sólidos totais suspensos } \\
\text { secos a } 103-105^{\circ} \mathrm{C} . \\
\end{array}$ & $\begin{array}{c}\text { Membranas } 1,2 \\
\text { Mufla 550 C: FORNITEC } 1940 \\
\text { Estufa 103을 C: LUFERCO }\end{array}$ \\
\hline $\mathrm{DQO}\left(\mathrm{mg} \mathrm{L}^{-1}\right)$ & $\begin{array}{l}5220 \text { C e adição de } \\
\text { padrão }\end{array}$ & Método do refluxo fechado & $\begin{array}{c}\text { Bloco digestor COD Reactor } \\
\text { HACH } \\
\text { Espectrofotômetro HACH } \\
\text { DR/2010 } \\
\end{array}$ \\
\hline COT (mg L-1) & $5310 \mathrm{~B}$ & $\begin{array}{c}\text { Método da combustão a alta } \\
\text { temperatura. }\end{array}$ & \\
\hline
\end{tabular}




\section{Then}

Fórum Ambiental

da Alta Paulista

ISSN 1980-0827

Volume 9, Número 11, 2013

Saúde, Saneamento e

Meio Ambiente

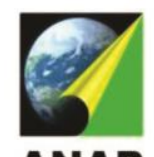

ANAP

\begin{tabular}{l|c|c|l}
\hline Cloreto $\left(\mathrm{mg} \mathrm{L}^{-1}\right)$ & $4500-\mathrm{Cl}$ B & Método de Mohr & \multicolumn{1}{|c}{$\begin{array}{c}\text { Agitador: FISATOM 761 } \\
\text { Bureta de 25 mL }\end{array}$} \\
\hline NKT $\left(\mathrm{mg} \mathrm{L}^{-1}\right)$ & $4500-$ Norg B e C & Micro-Kjeldhal & $\begin{array}{l}\text { pHmetro: Digimed DM-2P } \\
\text { Agitador: FISATOM 761 } \\
\text { Titulador: METROHM 20 mL } \\
\text { Destilador: BUCHI K-355 } \\
\text { Bloco Digestor BUCHI K-435 } \\
\text { Lavador de gases BUCHI B- } \\
414\end{array}$ \\
\hline $\begin{array}{l}\text { N-amoniacal } \\
\left(\mathrm{mg} \mathrm{L}^{-1}\right)\end{array}$ & $4500-\mathrm{NH3} \mathrm{B} \mathrm{e} \mathrm{C}$ & Destilação e titulação & $\begin{array}{l}\text { pHmetro: Digimed DM-2P } \\
\text { Agitador: FISATOM 761 } \\
\text { Titulador: METROHM 20 mL } \\
\text { Destilador BUCHI K-355 }\end{array}$ \\
\hline Nitrito (mg L-1) & $4500-$ NO2 B & Método colorimétrico & $\begin{array}{l}\text { Espectrofotômetro Agilent } \\
\text { Technologies Cary 60 UV-Vis }\end{array}$ \\
\hline Nitrato (mg L-1) & - & Cataldo (1975) & $\begin{array}{l}\text { Espectrofotômetro Agilent } \\
\text { Technologies Cary 60 UV-Vis }\end{array}$ \\
\hline
\end{tabular}

\subsection{Ensaios de ecotoxicidade}

Os organismos utilizados neste estudo foram: Pseudokirchineriella subcaptata, Ceriodaphnia dubia, Daphnia magna e Artemia salina, ilustrados nas fotos da Figura 1.

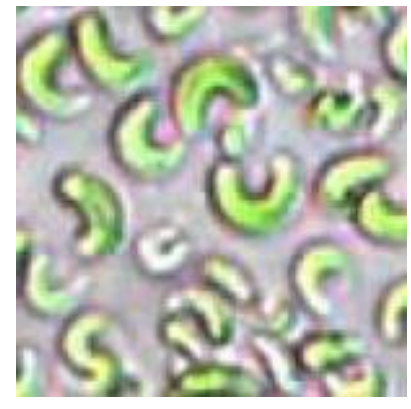

a

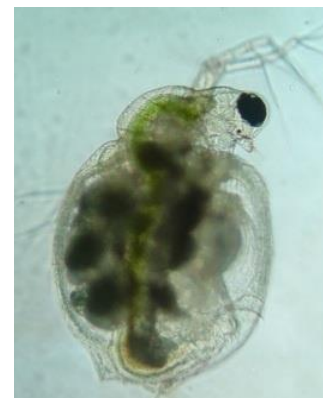

b

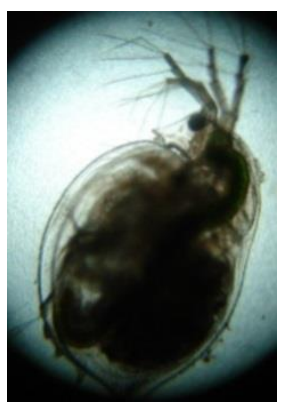

C

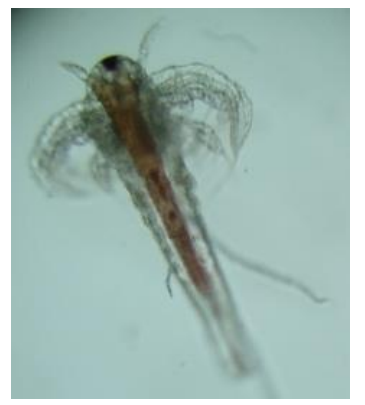

d

Figura 1 - Fotos dos organismos-teste utilizados nos ensaios de ecotoxicidade:

P. subcaptata (a), C. dubia (b), D. magna (c) e A. salina (d)

Fonte: Takenaka (2007), Kawahigashi (2012)

\section{- Pseudokirchneriella subcaptata}

O protocolo utilizado para a realização dos testes em $P$. subcaptata foi baseado na metodologia de Blaise et al. (2000). A validade dos testes para este ensaio de 
ecotoxicidade foi condicionada às seguintes premissas: o coeficiente de variação de cinco amostras controle, com tempo de exposição igual a 72 horas, não pode exceder a 40\%; e a densidade celular nos frascos de controle deve aumentar por um fator de no mínimo 16 $\left(1,16 \times 10^{5}\right.$ cél $\left.\mathrm{mL}^{-1}\right)$.

Para o ensaio, as diferentes concentrações das amostras de lixiviados diluídas, foram preparadas em vials de $5 \mathrm{~mL}$ contendo $2,5 \mathrm{~mL}$ de volume total, onde populações estimadas de $P$. subcaptata da ordem de $1,0 \times 10^{5}$ cél $\mathrm{mL}^{-1}$ foram expostas. Estes frascos permaneceram vedados com filme plástico transparente e incubados sob luz contínua por $72 \mathrm{~h}$ e a uma temperatura de $25^{\circ} \mathrm{C}$ com agitação três vezes ao dia (Tecnal - TE141).

Após este período, foi avaliada a toxicidade por meio da \% de inibição realizandose a contagem das células com auxílio de microscópio óptico (Motic- BA210), em câmara de Neubauer e os resultados foram tratados no programa Trimmed Spearman-Karber (Hamilton et al., 1977) com intervalo de confiança de $95 \%$ e expressos em $\mathrm{Cl}_{50}{ }_{72 \mathrm{~h}}$ concentração de inibição média que causa um efeito crônico a 50\% dos organismos após $72 \mathrm{~h}$ de exposição.

\section{- Ceriodaphnia dubia}

Os ensaios de ecotoxicidade utilizando Ceriodaphnia dubia consistiram na exposição de 5 neonatas com idade entre 6 e 24 h para diferentes diluições das amostras de lixiviados com água reconstituída para volume total de $10 \mathrm{~mL}$ em placas de cultivo celular em polipropileno (TPP). Para cada concentração da amostra e controles negativo (água reconstituída) e positivo (dicromato de potássio $0,05 \mathrm{~g} \mathrm{~L}^{-1}$ ) foram feitas 3 réplicas. Os experimentos foram mantidos a temperatura controlada de $25^{\circ} \mathrm{C}$, sem iluminação e sem alimentação. No início e final dos testes foram realizadas as medidas dos parâmetros de $\mathrm{pH}$, condutividade, oxigênio dissolvido (OD) e dureza.

Após o período de exposição foi realizada a contagem dos organismos imóveis e mortos em esteroscópio (Motic - SMZ140 FBLED) e seus resultados foram expressos como concentração efetiva mediana da amostra que causa efeito a $50 \%$ da população exposta após $24 \mathrm{~h}$ - CE50 $24 \mathrm{~h}$ e 48 h - CE5048h obtidas por cálculo estatístico usando o 
programa Trimmed Spearman-Karber com intervalo de confiança de 95\% (HAMILTON et al. 1977). O ensaio foi validado se a porcentagem de organismos imóveis ou mortos no controle negativo resultasse inferior a 10\% (ABNT, 2005).

\section{- Daphnia magna}

Os ensaios de ecotoxicidade em Daphnia magna consistiram na exposição de 5 neonatas com idade entre 2 e $26 \mathrm{~h}$ para diferentes diluições das amostras de lixiviados com água de cultivo meio M4 para volume total de $10 \mathrm{~mL}$ em placas de cultivo celular em polipropileno (TPP). Para cada concentração da amostra e controle negativo (água de cultivo meio M4) e positivo (dicromato de potássio $0,05 \mathrm{~g} \mathrm{~L}^{-1}$ ) foram feitas 3 réplicas. Os experimentos foram mantidos a temperatura controlada de $25^{\circ} \mathrm{C}$, sem iluminação e sem alimentação. No início e final dos testes foram realizadas as medidas dos parâmetros de $\mathrm{pH}$, condutividade, oxigênio dissolvido (OD) e dureza.

Após o período de exposição foi realizada a contagem dos organismos imóveis e mortos em esteroscópio (Motic - SMZ140 FBLED) e seus resultados foram expressos como concentração efetiva mediana da amostra que causa efeito a $50 \%$ da população exposta após $24 \mathrm{~h}-\mathrm{CE} 50_{24 \mathrm{~h}}$ e $48 \mathrm{~h}-\mathrm{CE}_{4} \mathrm{H}_{48 \mathrm{~h}}$ obtidas por cálculo estatístico usando o programa Trimmed Spearman-Karber com intervalo de confiança de 95\% (Hamilton et al., 1977). O ensaio foi validado se a porcentagem de organismos imóveis ou mortos no controle negativo resultasse inferior a 10\% (ABNT, 2004).

\section{- Artemia salina}

Segundo Kawahigashi (2012), os ensaios de ecotoxicidade para o organismo $A$. salina devem ser realizados com ajuste de pH para valores entre 8,0 e 9,0 e condição mínima de salinidade de $10 \%$ de solução salina para que não haja comprometimento na interpretação dos resultados em relação à toxicidade da amostra testada. 
Para a eclosão dos ovos de Artemia salina, estes foram incubados por 48 horas em solução salina artificial com pH entre 8 e 9 e à temperatura de $27^{\circ}$ a $30^{\circ} \mathrm{C}$ com iluminação constante de $60-100 \mathrm{w}$.

Os ensaios foram realizados em tubos de ensaio de $10 \mathrm{~mL}$ em 4 réplicas para cada uma das concentrações das amostras de lixiviados, controles negativo e positivo para um volume total de $5 \mathrm{~mL}$. Foram colocados 10 náuplios de $A$. salina por tubo, e estes foram mantidos sob iluminação à temperatura de $27^{\circ}$ a $30^{\circ} \mathrm{C}$ por $24 \mathrm{~h}$.

Após a exposição de 24 h, o número de organismos vivos e mortos em cada tubo era quantificado para posteriormente determinar a concentração da amostra que causou mortalidade de 50\% dos organismos após exposição de $24 \mathrm{~h}$ - CL5024h nas condições do teste. A CL5024h foi obtida por cálculo estatístico usando o programa Trimmed Spearman-Karber (HAMILTON et al., 1977) com intervalo de confiança de 95\%.

\section{RESULTADOS E DISCUSSÃO}

\subsection{Caracterização física e química do lixiviado}

Na Tabela 3 são apresentados os resultados da caracterização física e química do lixiviado bruto, do lixiviado tratado preliminarmente por stripping de amônia seguido de tratamento biológico por lodos ativados e do lixiviado pós-tratado por coagulaçãofloculação-sedimentação.

Tabela 3 - Caracterização física e química do lixiviado bruto, tratado preliminarmente por stripping de amônia seguido de tratamento biológico por lodos ativados e do lixiviado pós-tratado por coagulaçãofloculação-sedimentação. 


\begin{tabular}{|c|c|c|c|c|c|c|}
\hline PARÂMETRO & UNIDADE & LIX & $\mathrm{BIO}$ & \% REMOÇÃO & CFS & \% REMOÇÃO \\
\hline $\mathrm{pH}$ & - & 8,9 & 8,5 & - & 4,1 & - \\
\hline Alcalinidade & $\mathrm{mg} \mathrm{CaCO}_{3} \mathrm{~L}^{-1}$ & 1914 & 1608 & 16 & 0 & 100 \\
\hline Temperatura & $\stackrel{\circ}{ } \mathrm{C}$ & 23,7 & 23,6 & - & 23,5 & - \\
\hline Cor aparente & $\mathrm{uH}$ & 4031 & 3504 & 13 & 75 & 98 \\
\hline Cor verdadeira & $\mathrm{uH}$ & 3598 & 3393 & 6 & 38 & 99 \\
\hline NKT & $\mathrm{mg} \mathrm{N} \mathrm{NH}_{3} \mathrm{~L}^{-1}$ & 304 & 67 & 78 & 15 & 78 \\
\hline $\mathrm{N}$-amoniacal & $\mathrm{mg} \mathrm{N} \mathrm{NH}_{3} \mathrm{~L}^{-1}$ & 236 & 5 & 98 & 2 & 60 \\
\hline Nitrito & $\mathrm{mg} \mathrm{N}-\mathrm{NO}_{2} \mathrm{~L}^{-1}$ & 105 & 3 & 97 & 0 & 100 \\
\hline Nitrato & $\mathrm{mg} \mathrm{N}-\mathrm{NO}_{3} \mathrm{~L}^{-1}$ & 21 & 3 & 84 & 0 & 100 \\
\hline Cloreto & $\mathrm{mg} \mathrm{L}^{-1}$ & 1828 & 1935 & - & 3161 & - \\
\hline DQO & $\mathrm{mg} \mathrm{O}_{2} \mathrm{~L}^{-1}$ & 1344 & 1144 & 15 & 379 & 67 \\
\hline ST & $\mathrm{mg} \mathrm{L}^{-1}$ & 5554 & 6456 & - & 6330 & - \\
\hline SST & $\mathrm{mg} \mathrm{L}^{-1}$ & 232 & 73 & - & 22 & - \\
\hline SDT & $\mathrm{mg} \mathrm{L}^{-1}$ & 5322 & 6383 & - & 6308 & - \\
\hline
\end{tabular}

\subsection{Ensaios de ecotoxicidade}

Nos ensaios de ecotoxicidade crônica em P.subcapitata avaliou-se o efeito de inibição após $72 \mathrm{~h}$ de exposição. Já nos ensaios de ecotoxicidade aguda em $C$. dubia, $D$. magna e $A$. salina foram avaliados os efeitos de imobilidade e letalidade após 24 e $48 \mathrm{~h}$ de exposição para $C$. dubia e $D$. magna e de 24 h de exposição para $A$. salina.

Nos Gráficos 1 a 3 são apresentados os resultados obtidos para os ensaios de ecotoxicidade expressos em $\mathrm{Cl}_{50} 0_{72 \mathrm{~h}}$ para $P$.subcapitata, $\mathrm{CE} 50_{24 \mathrm{~h}}$ e $\mathrm{CE} 50_{48 \mathrm{~h}}$ para $C$. dubia e $D$. magna e $\mathrm{CL}_{50}$ 24h para $A$. salina em relação às amostras de lixiviado bruto (LIX), lixiviado após tratamento preliminar por stripping de amônia seguido de tratamento biológico (BIO) e lixiviado pós-tratado por coagulação-floculação-sedimentação (CFS), respectivamente. 
Gráfico 1 - Ensaio de ecotoxicidade para o lixiviado bruto - LIX em diferentes organismos-teste

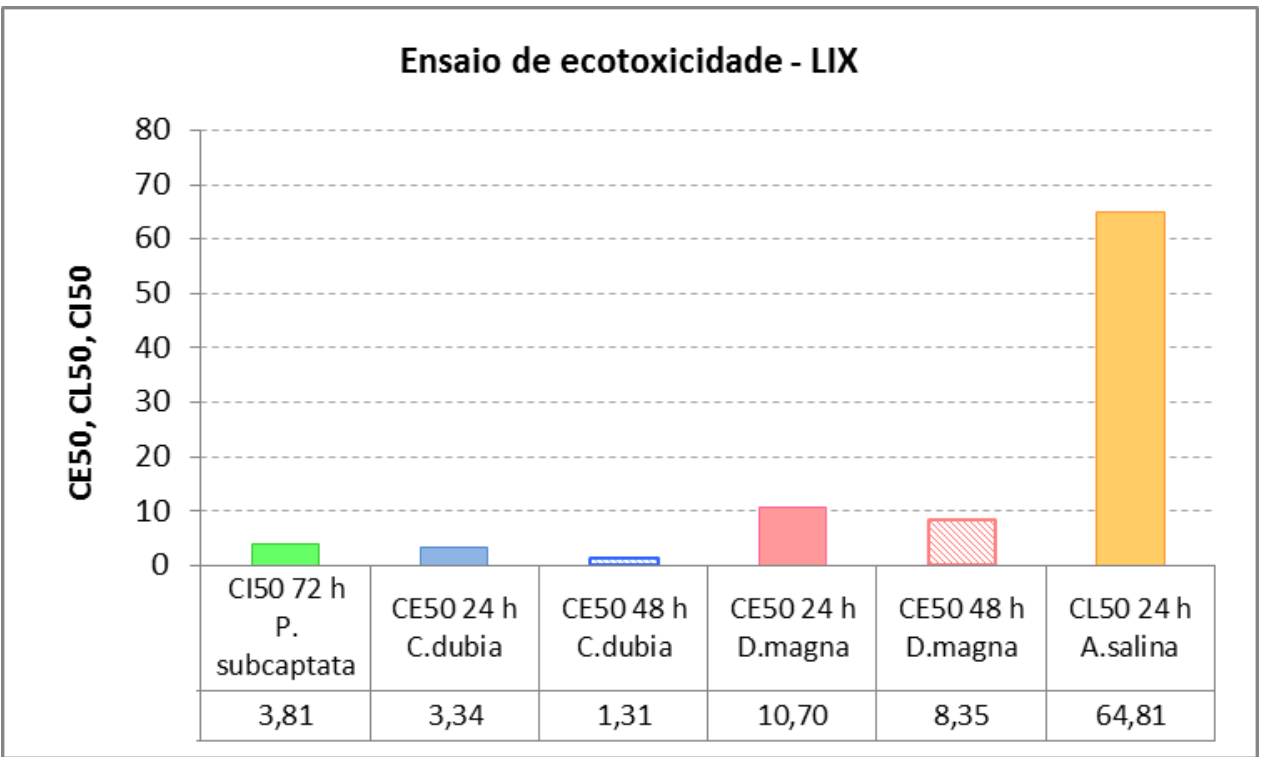

Gráfico 2 - Ensaio de ecotoxicidade para o lixiviado após tratamento preliminar por stripping de amônia seguido de tratamento biológico por lodos ativados - BIO em diferentes organismos-teste

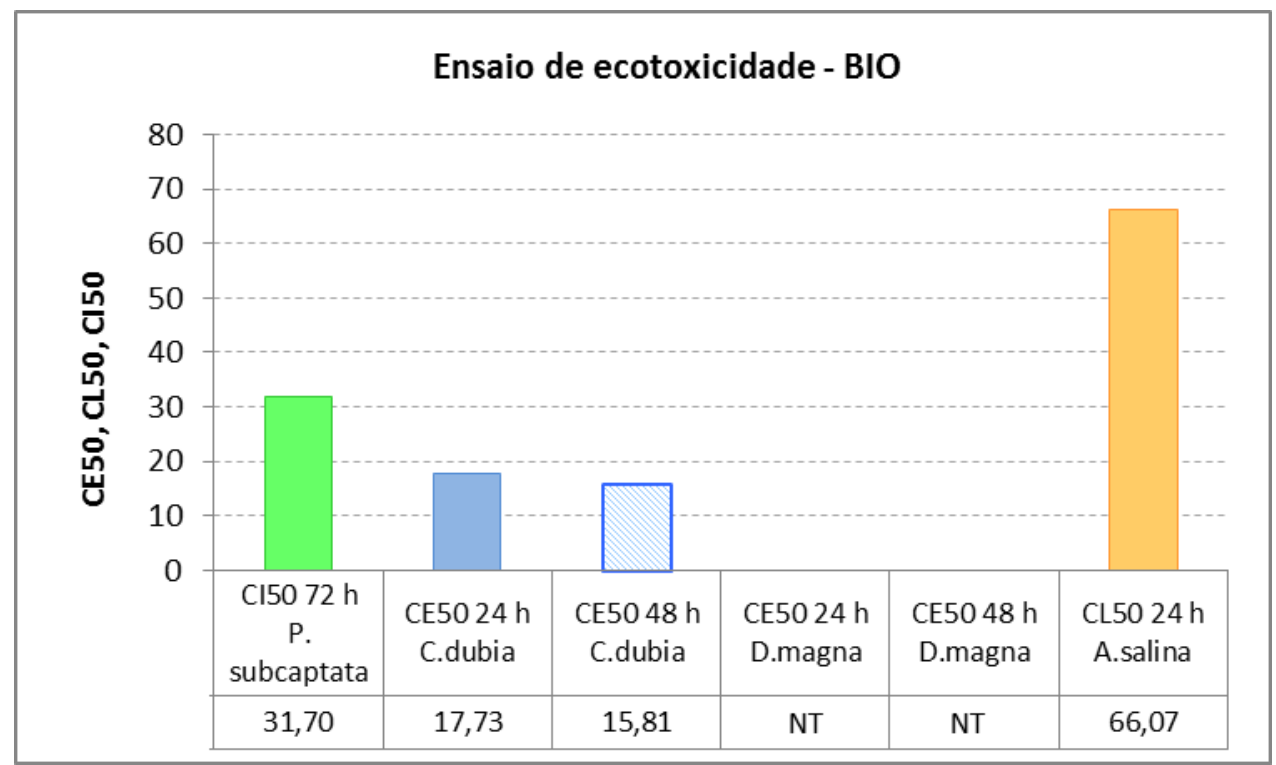

NT= Não tóxico

Gráfico 3 - Ensaio de ecotoxicidade para lixiviado após tratamento por coagulação-floculação-sedimentação - CFS em diferentes organismos-teste 


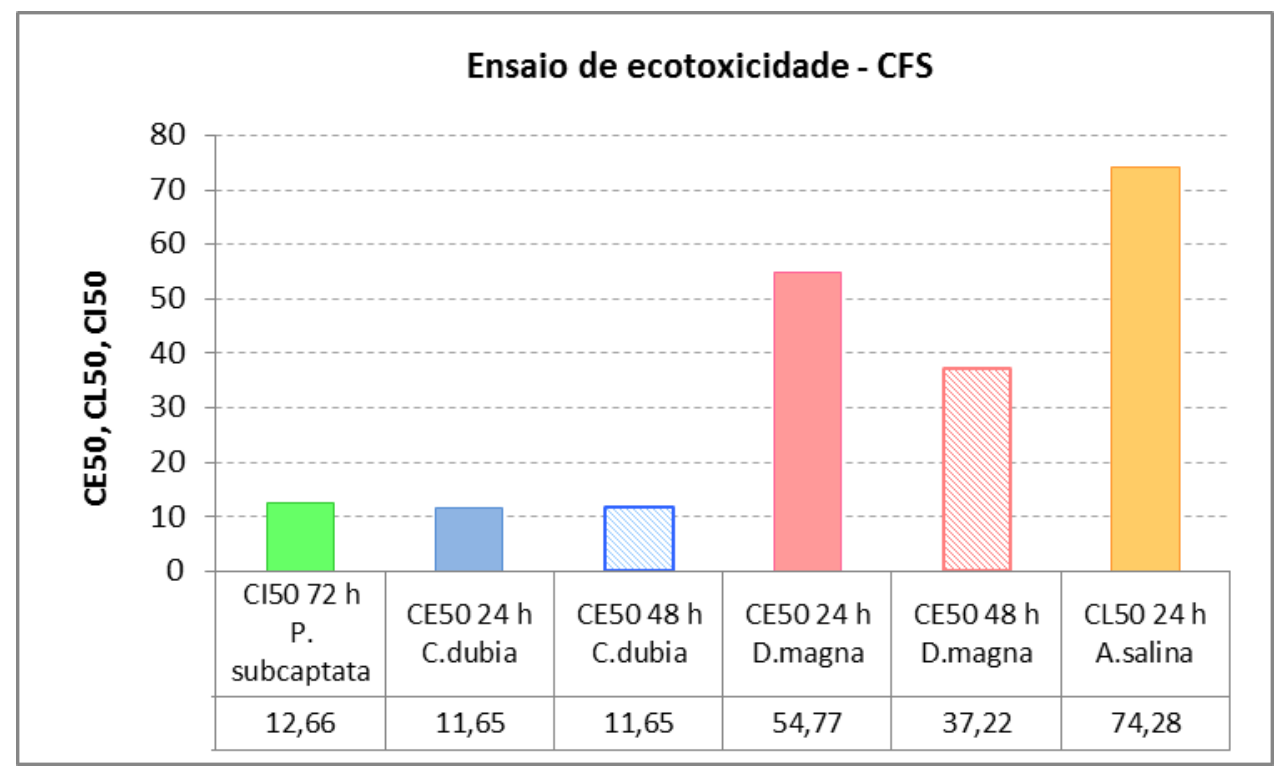

Os valores obtidos de $\mathrm{CE}_{50} \mathrm{H}_{24 \mathrm{~h}}$ e $\mathrm{CE} 5 \mathrm{5}_{48 \mathrm{~h}}$ em $D$. magna para o lixiviado bruto foram 10,70 e 8,35, respectivamente (Gráfico 1). Já para o lixiviado após tratamento biológico, não foi possível determinar a $\mathrm{CE} 50_{24 \mathrm{~h}}$ e $\mathrm{CE} 50_{48 \mathrm{~h}}$ em $D$. magna, pois não foram observados efeitos de imobilidade e/ou letalidade para as concentrações testadas.

Considerando-se os resultados obtidos de $\mathrm{Cl}_{50} \mathrm{7}_{72 \mathrm{~h}}$ em P.subcapitata e $\mathrm{CE} \mathrm{CO}_{24 \mathrm{~h}} \mathrm{e}$ $\mathrm{CE}_{50}{ }_{48 \mathrm{~h}}$ em C. dubia do lixiviado bruto e após tratamento preliminar por stripping de amônia seguido de tratamento biológico por lodos ativados, pode-se observar que a toxicidade foi reduzida de valores entre 1,31 a 3,81 para valores entre 15,81 e 31,70 (Gráficos 1 e 2).

Estes fatos podem estar relacionado à presença de nitrogênio na forma de amônia, tóxica aos organismos e presente em concentrações de $236 \mathrm{mg}^{-\mathrm{L}^{-1}}$ no lixiviado bruto, e de sua remoção no lixiviado após tratamento biológico de 98\% (Tabela 3), comprovando assim a eficiência desse tipo de tratamento. Resultados similares foram encontrados por Kawahigashi (2012), em que a toxicidade do lixiviado bruto foi reduzida de valores entre 0,9 e 4,7 para valores entre 20,6 e 30,1 após tratamento biológico. Gotvan et al., (2009) obtiveram valores de $\mathrm{CE}_{50} \mathrm{2}_{24}: 3,7$ e $\mathrm{CE} 50_{48 \mathrm{~h}}: 3,2$, para lixiviado bruto em $D$. magna. Valores semelhantes também foram reportados por Martins el al. (2010) com valores de $\mathrm{CE}_{40}{ }_{48 \mathrm{~h}}$ entre 2,28 - 3,12 em D. magna. 
Apesar da eficiência do pós-tratamento por coagulação-floculação-sedimentação em relação à remoção de cor aparente e verdadeira e DQO (Tabela 3), a toxicidade do lixiviado após este tratamento foi aumentada. Para o organismo $D$. magna, no qual não foram observados efeitos de imobilidade e/ou letalidade após o tratamento biológico, foram obtidos valores de $\mathrm{CE}_{50} \mathrm{2}_{24 \mathrm{~h}}$ e $\mathrm{CE} 5 \mathrm{5}_{48 \mathrm{~h}}$ de 54,77 e 37,22 para o lixiviado pós-tratado por coagulação-floculação-sedimentação. Comportamento análogo foi observado em relação aos valores de $\mathrm{Cl}_{50} 0_{72 \mathrm{~h}}$ em P.subcapitata, $\mathrm{CE} 50_{24 \mathrm{~h}}$ e $\mathrm{CE}_{50} 0_{48 \mathrm{~h}}$ em C. dubia que variaram entre 11,65 e 12,66 .

Assim como argumentado por Kawahigashi (2012), este aumento de toxicidade pode estar associado aos produtos químicos empregados na coagulação química e aos residuais de metais como Fe entre outros e cloretos provenientes do coagulante químico (cloreto férrico) utilizado durante este pós-tratamento.

Contrariando as respostas obtidas pelos demais organismos-teste utilizados, podese verificar que a toxicidade do lixiviado bruto para Artemia salina foi reduzida gradativamente após cada tratamento apresentando valores de $\mathrm{CL}_{50} \mathrm{O}_{24 \mathrm{~h}}$ iguais a 64,81; 66,07 e 74,28 para o lixiviado bruto, após tratamento biológico e pós-tratamento por coagulação-floculação-sedimentação, respectivamente.

Esses resultados inferem que a sensibilidade da $A$. salina difere dos demais, fato que pode estar relacionado por esse organismo ser de origem marinha e ser mais resistente ao cloreto, possível agente tóxico à $D$. magna e $C$. dubia que são organismos de água doce.

O Gráfico 4 apresenta os valores obtidos de fatores de toxicidade - FT, ou seja, a menor diluição da amostra na qual não se observa o efeito deletério sobre os organismosteste: C. dubia, D. magna e A. salina. A Resolução 081/2010 do Cema dispõe critérios e padrões de toxicidade aguda para o controle de efluentes líquidos lançados em águas superficiais e limita o valor de FT de 8 (12,5\%) em Daphnia magna e Vibrio fischeri para efluentes com despejo em corpos hídricos de água doce. Além disso, estabelece em seu Artigo 3o o limite máximo de FT igual a 4 a partir do quarto ano de sua publicação, e FT igual a 2 a partir do oitavo ano. 
Considerando-se os resultados obtidos de FT em D. magna, pode-se observar que o fator foi superior a 8 para o lixiviado bruto. No entanto, para o lixiviado tratado preliminarmente por stripping de amônia seguido de tratamento biológico o valor de FT foi de 1,05 apresentando-se dentro dos limites estabelecidos mesmo considerando as metas progressivas mais restritivas, ou seja, para oito anos visando reduzir a ecotoxicidade aguda para melhoria da qualidade dos corpos hídricos. Já para o lixiviado pós-tratado por coagulação-floculação-sedimentação, o FT de 3,33, atende ao limite para meta progressiva estabelecida a partir do quarto ano de sua publicação (Gráfico 4).

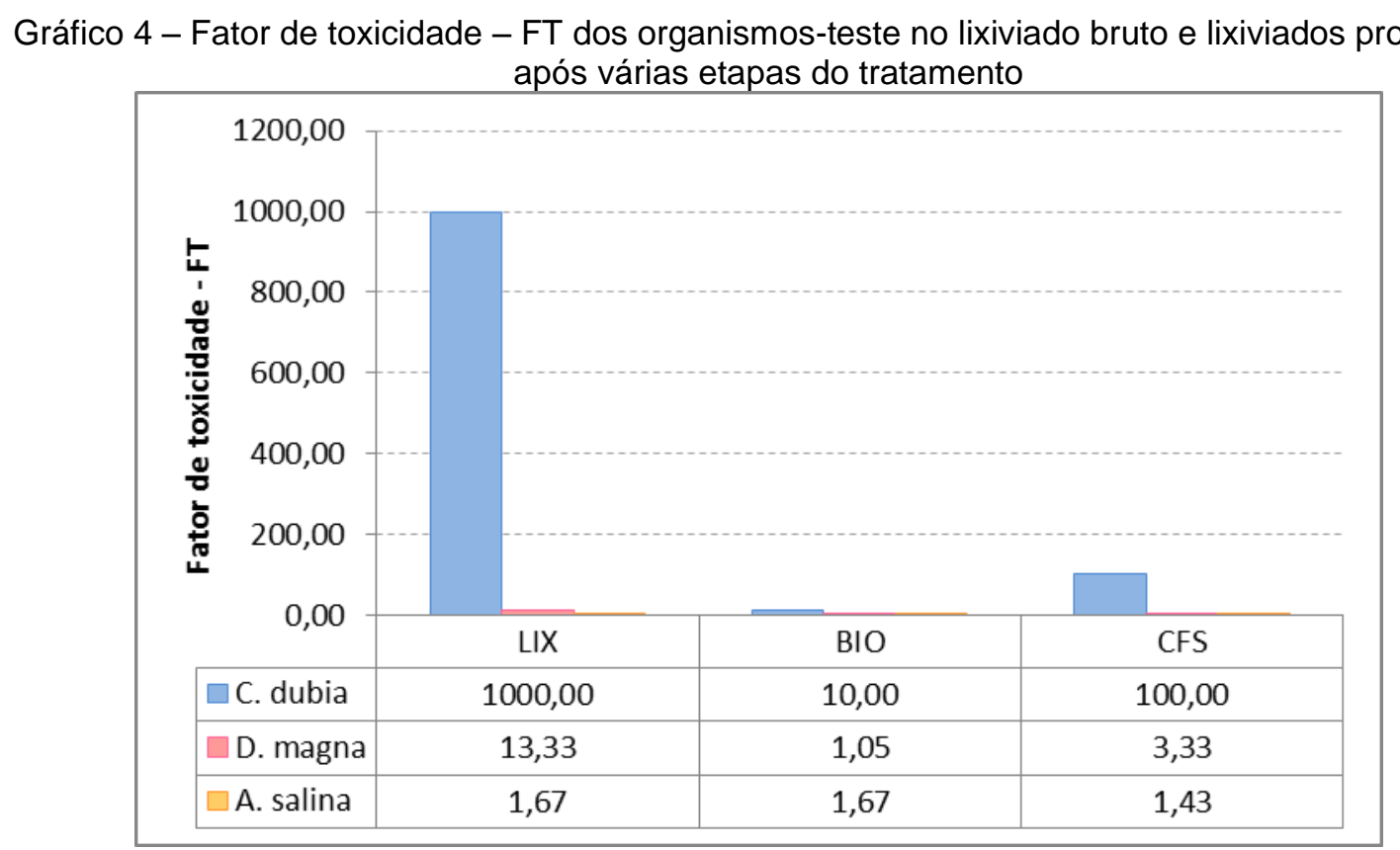

As respostas de sensibilidade dos organismos-teste utilizados nos ensaios de ecotoxicidade foram diferenciadas em relação aos compostos presentes nos lixiviados. Isso ocorre devido as suas características morfológicas e também pelo habitat em que vivem. Diante deste fato, para a avaliação do efeito tóxico de uma amostra é recomendável que os ensaios de ecotoxicidade sejam realizados com organismos pertencentes a diferentes níveis tróficos da cadeia alimentar tais como, microalgas, 
microcrustáceos, equinoides, poliquetas, oligoquetas, peixes e bactérias, abrangendo assim os mais diversos ecossistemas e níveis tróficos.

\section{CONCLUSÕES}

Os ensaios de ecotoxicidade e os valores de CE50 ${ }_{72 \mathrm{~h}}$ em $P$ subcapitata, CE50 ${ }_{24 \mathrm{~h}} \mathrm{e}$ $\mathrm{CE}_{50}{ }_{48 \mathrm{~h}}$ para $C$. dubia e $D$. magna e $\mathrm{CL}_{50}$ 24h para $A$. salina, mostraram que o lixiviado tratado biologicamente apresentou uma menor toxicidade frente aos organismos testados em comparação com o lixiviado bruto, o que demonstra a eficiência do tratamento biológico empregado para a remoção da carga de contaminantes que causam toxicidade. Por outro lado as características físico-químicas do lixiviado após tratamento biológico revelaram a necessidade de pós-tratamento visando a remoção de compostos recalcitrantes.

Já para o lixiviado pós-tratado por coagulação-floculação-sedimentação, apesar da remoção significativa de compostos recalcitrantes, houve aumento da toxicidade para $P$ subcapitata, C. dubia e D. magna, provavelmente devido aos residuais de metais e cloretos provenientes do coagulante químico (cloreto férrico) utilizado durante este póstratamento. No entanto este aumento de toxicidade ainda atende ao limite para meta progressiva para $D$. magna estabelecida pela Resolução 081/2010 do Cema.

Dentre os organismos-teste utilizados, a $A$. salina apresentou respostas atípicas em relação aos demais organismos e a toxicidade do lixiviado bruto foi reduzida gradativamente após cada tratamento, fato que pode estar relacionado por esse organismo ser de origem marinha e ser mais resistente ao cloreto, possível agente tóxico à $P$ subcapitata, $C$. dubia e $D$. magna que são organismos de água doce.

\section{REFERÊNCIAS}

APHA, AWWA, WEF, Standard Methods For The Examination Of Water \& Wastewater 21st Edition, 2005. 
ASSOCIAÇÃO BRASILEIRA DE NORMAS TÉCNICAS. Ecotoxicologia aquática Toxicidade crônica - Método de ensaio com Ceriodaphnia spp (Crustacea, Cladocera). NBR 13373. São Paulo, 2005.

ASSOCIAÇÃO BRASILEIRA DE NORMAS TÉCNICAS. Ecotoxicidade aguda - Método de ensaio com Dapnhia spp (Cladocera, Crustacea). NBR 12713. São Paulo, 2004.

BLAISE, C.; FORGET, G.; TROTTIER, S. Toxicity screening of aqueous samples using a cost-effective 72-h exposure Selenastrum capricornutum assay. Journal of Environmental Toxicology. New York, v. 15, p. 352-359, 2000. Special Issue:Watertox Bioassays.

BRASIL, Ministério do Meio Ambiente. Conselho Nacional de Meio Ambiente. Resolução $n^{\circ}$ 357, 17 de março de 2005. Dispõe sobre a classificação dos corpos de água e diretrizes ambientais para o seu enquadramento, bem como estabelece as condições e padrões de lançamento de efluentes, e dá outras providências. Brasília, 2005.

BRASIL, Ministério do Meio Ambiente. Conselho Nacional do Meio Ambiente. Resolução $n^{\circ} \mathbf{4 3 0}$ de 13 de maio de 2011. Complementa e altera a Resolução no 357 de 2005, Brasília, 2011.

HAMILTON, M.A.; RUSSO, R.C.; THURSTON, R.V. (1977). Trimmed Spearman-Karber Method for Estimating Median Lethal Concentration in Toxicity Bioassays. Environmental Science \& Technology, Easton, v.11, n.7, p.714-719.

KAWAHIGASHI, F. Pós-tratamento de Lixiviado de Aterro sanitário por Adsorção em Carvão Ativado Granular com Avaliação Ecotoxicológica. Dissertação apresentada ao Programa de Pós-Graduação em Engenharia de Edificações e Saneamento. Universidade Estadual de Londrina. Londrina, 2012.

MAGALHÃES, D.P.; FERRÃO FILHO, A.S. A ecotoxicologia como ferramenta no biomonitoramento de ecossistemas aquáticos. Oecol. Bras. 12(3), p. 355-381, 2008. 
PARANÁ, Conselho Nacional do Meio Ambiente. Resolução 081/2010 - CEMA. Dispõe sobre Critérios e Padrões de ecotoxicidade para o Controle de Efluentes Líquidos lançados em águas superficiais no Estado do Paraná. Curitiba, 2010.

PARANÁ, Conselho Nacional do Meio Ambiente. Resolução 0070/2009 - CEMA. Dispõe sobre o licenciamento ambiental, estabelece condições e critérios e dá outras providências, para Empreendimentos Industriais. Curitiba, 2009.

TAKENAKA, R.A. Avaliação da toxicidade de Microcystis aeruginosa e de florações naturais de cianobactérias de reservatórios do rio Tietê, SP. Tese apresentada à Escola de Engenharia de São Carlos. São Carlos, 2007. 